\title{
ĐÁNH GIÁ TÁC ĐỘNG CỦA BIẾN ĐỔI KHÍ HậU LÊN HẠN HÁN TRÊN LƯU VỰC SÔNG SÊSAN
}

\author{
Vũ Đức Long', Nguyễn Ngọc Hoa ${ }^{1}$
}

Tóm tắt: Bài báo với nội dung đánh giá tác động của biến đổi khi hậu (BĐKH) lên chế độ hạn khí tuợng và hạn thủy văn trong nhũng tháng mùa khô trên lưu vực sông Sê San thông qua các chỉ số hạn và mô hình toán thủy văn. Trong nghiên cứu này, hai kịch bản BĐKH cho luợng mưa và nhiệt độ là RCP4.5 và RCP8.5 tù mô hình khí hậu toàn cầu GCMs (Global Climate Models) của dụ án CMIP5 (Coupled Model Intercomparison Project 5) đã được chi tiết hóa thống kê cho lưu vưc sông Sê San. Hạn khí tương được tính toán bằng chi số chuẩn hóa lượng mưa SPI, hạn thủy văn được xây dựng dự trên chỉ số K hạn, lưu lương dòng chảy trong tưong lai được mô phỏng tù mô hình thủy văn SWAT cho lưu vục sông Sê San. Kết quả nghiên cưu trong turong lai cho thấy hạn khí turợng xảy ra nhiều nhất vào giai đoạn tù 2080 đến 2099 vớ tổng số sụ kiện hạn được ghi nhận khoảng 41 sụ kiện và được đánh giá trên số liệu mura tù các trạm khí tượng (trong đó có khoảng 35\% hạn vùra, 47\% hạn nặng và 18\% hạn nghiêm trọng cho kịch bản RCP 8.5). Tù kết quả mô phỏng dòng chảy trong twơng lai và tính toán chỉ số hạn thủy văn cho lưu vục, nghiên cứu cũng đã đưa ra bản đồ phân vùng hạn thủy văn cho nhũng năm xảy ra hạn nghiêm trọng, nhận thấy các tiểu lưu vục thuộc khu vực tỉnh Gia Lai sẽ chịu tổn thương bởi các mưc độ hạn nhiều nhất trên lưu vực Sê San.

Từ khóa: Biến đổi khí hậu, chỉ số hạn, mô hình SWAT, lưu vục sông Sê San.

Ban Biên tập nhận bài: 05/11/2019 Ngày phản biện xong: 31/12/2019 Ngày đăng bài: 25/02/2019

\section{Giới thiệu}

Biến đồi khí hậu hiện đang diễn ra trên phạm vi toàn cầu, Việt Nam là một trong những nước dễ bị tổn thương nhất thế giới trước những tác động của biến đổi khí hậu, một trong những tác động đó là hiện tượng hạn hán, thiếu nước trầm trọng gây ảnh hưởng lớn đến đời sống cũng như các hoạt động kinh tế xã hội. Để ứng phó với hạn hán trong tương lai thì việc dự báo cũng như đánh giá mức độ hạn là quan trọng để có thể đưa ra được các hoạch định, kế hoạch trong quản lý tài nguyên nước, giảm thiểu mức độ nguy hại của hạn hán. Khu vực Tây Nguyên là một trong những vùng thường xuyên bị khô hạn ở nước ta, hệ thống sông suối tuy khá phát triển nhưng do địa hình dốc, chiều dài dòng chảy ngắn nên vào mùa mưa thường chảy xiết, mùa khô thì hầu như khô kiệt, do đó nguồn nước mặt khá hạn chế. Gần đây nhất dưới tác động của hiện tượng El Nino trong năm 2015-2016, hạn hán đã diễn ra khốc liệt nhất trong 15 năm qua ở khu vực Tây Nguyên, lượng nước trên các ao hồ, công trình thủy lợi rơi vào tình trạng cạn kiệt và gây thiệt hại lớn cho ngành nông nghiệp. Theo số liệu thống kê thiệt hại của một số địa phương: Tây Nguyên đã có gần 175.000 ha cây trồng bị ảnh hưởng hạn hán (Kon Tum 3.800 ha, Gia Lai 46.000 ha, Đắk Lắk 80.000 ha, Đắk Nông 23.000 ha, Lâm Đồng 31.300 ha); Tổng kinh phí thiệt hại toàn vùng lên đến gần 4.000 tỷ đồng (Kon Tum 160 tỷ, Gia Lai 200 tỷ, Đắk Lắk 2.200 tỷ, Đắk Nông 1.200 tỷ và Lâm Đồng 180 tỷ). Nghiên cứu này lựa chọn lưu vực sông Sê San để đánh giá mức độ hạn hán dưới tác động của

${ }^{1}$ Trung tâm dụ báo Khí tượng Thủy văn quốc gia Email:longkttv@gmail.com 
biến đổi khí hậu, sông Sê San là một trong hai lưu vực sông lớn của Tây Nguyên.

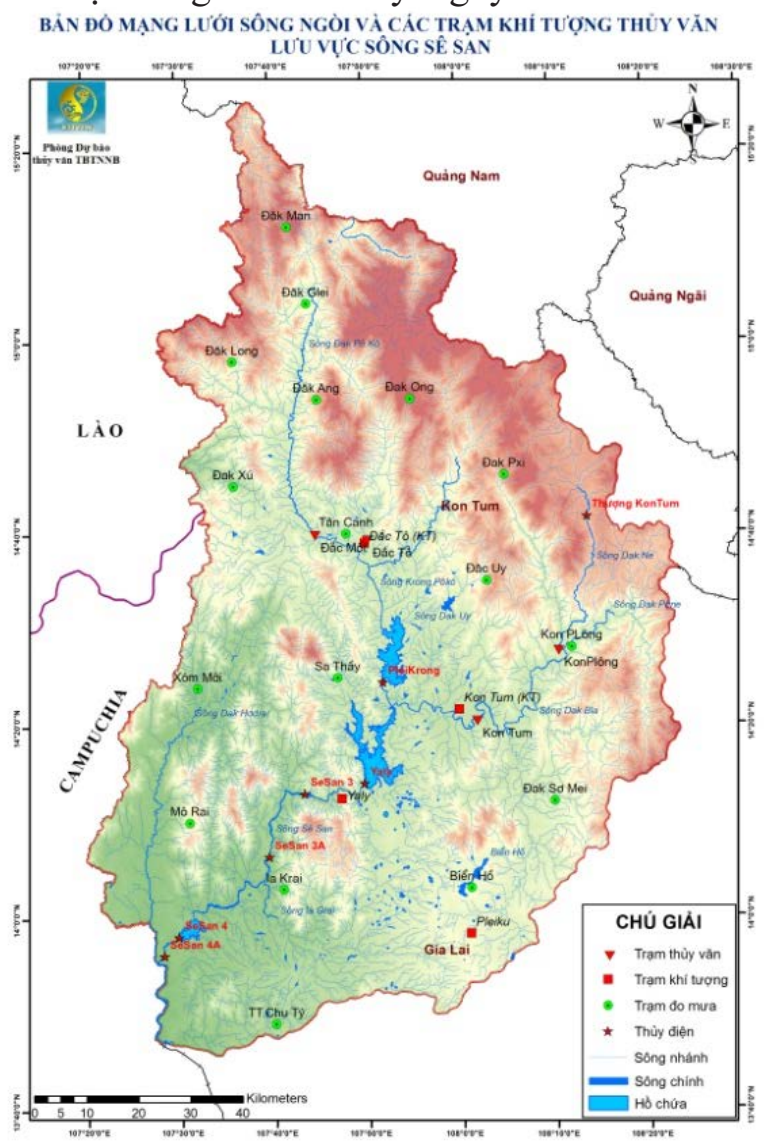

Hình 1. Lưu vực sông Sê San

Sông Sê San là một trong các nhánh lớn của hạ du lưu vực sông Mê Kông. Sông Sê San được bắt nguồn từ vùng núi cao Ngọc Linh tỉnh Kon Tum thuộc phía Bắc Tây Nguyên của Việt Nam, chảy sang Campuchia và nhập lưu với các sông Srêpôk, Sê Kông sau đó nhập vào sông Mê Kông ở Strung Treng. Trên lãnh thổ Việt Nam, sông Sê San nằm trên 2 tỉnh Kon Tum và Gia Lai với chiều dài $230 \mathrm{~km}$, diện tích lưu vực $11.620 \mathrm{~km}^{2}$. Lưu vực có tọa độ địa lý $13^{\circ} 45^{\prime}$ ' đến $15^{\circ} 14^{\prime}$ vĩ độ Bắc; toạ độ $107^{\circ} 10^{\prime}$ đến $108^{\circ} 24^{\prime}$ kinh độ Đông. Lưu vực sông Sê San trên lãnh thổ Việt Nam chiếm 46,3\% diện tích tự nhiên của 2 tỉnh Kon Tum và Gia Lai, trong đó nằm trên địa phận của Kon Tum $87,61 \%$ diện tích toàn tỉnh, Gia Lai 20,63\% thuộc đất đai của 14 huyện, thị, thành phố Đắc Glêi, Đăc Tô, Đắc Hà, Ngọc Hồi, Sa Thầy, Kon Plong, Kon Rẫy, Tu Mơ Rông, Chư Pah, Ia Grai, Đức Cơ, Đắc Đoa, thành phố Kon Tum và Plêi Ku.
Dựa vào chỉ số chuẩn hóa lượng mưa (SPI Standardized Precepitation Index), nghiên cứu sẽ đánh giá các mức độ hạn trong các giai đoạn trong tương lai từ số liệu mưa của mô hình toàn cầu. Từ số liệu mưa và nhiệt độ trong tương lai, mô hình SWAT được sử dụng để mô phỏng chế độ dòng chảy cho lưu vực sông Sê San, từ đó tính toán hệ số hạn thủy văn - được xây dựng dựa trên chỉ số $\mathrm{K}$ hạn (biểu thị mức độ khô và cạn cho thời điểm xuất hiện và nơi sinh hạn cụ thể).

\section{Phương pháp nghiên cứu}

\subsection{Số liệu sử dụng}

Số liệu mưa, nhiệt độ ngày và lưu lượng ngày từ năm 1980 đến năm 2016 của các trạm khí tượng thủy văn trong lưu vực bao gồm: Đắk Tô, Đắk Mốt, KonPlong, KonTum, Plêi Ku; mạng lưới sông suối và vị trí các trạm đo khí tượng, thủy văn trên lưu vực sông Sê San.

Mô hình cao độ số (DEM) với độ phân giải $30 \mathrm{mx} 30 \mathrm{~m}$ được thu thập từ dữ liệu cao độ số toàn cầu ASTER của NASA. Dữ liệu thảm phủ được thu thập từ Global Land Cover 2000 - GLC 2000. Dữ liệu thổ nhưỡng được thu thập từ Harmonized World Soil Database - HWSD.

Số liệu đầu ra của 27 GCMs từ dự án CMIP5 thông qua phần mềm AIMS thuộc bản quyền của trung tâm khí hậu APEC cho hai kịch bản $\mathrm{BDKH}$ là $\mathrm{RCP} 4.5$ và RCP 8.5 trong quá khứ và tương lai từ năm 1980 đến năm 2099 (dữ liệu được liệt kê trong bảng 1 dưới đây).

\subsection{Lựa chọn mô hình khí hậu toàn cầu GCMs cho lưu vực sông Sê San tù̀ CMIP5}

Số liệu khí tượng thu thập được từ đầu ra của các mô hình GCMs thường có độ phân giải cao, bởi vậy số liệu khí tượng cần được chi tiết hóa đến khu vực nghiên cứu để tăng độ chính xác cho việc đánh giá kết quả. Ứng dụng phần mềm AIMS [1] của trung tâm khí hậu APEC, từ số liệu thực đo đầu vào gồm mưa và nhiệt độ của lưu vực sông Sê San của các trạm Đắk Tô, Đắk Mốt, KonPlong, KonTum, PlêiKu từ năm 1980 đến 2010, nghiên cứu thu được số liệu từ 27 mô hình khí hậu toàn cầu sau khi đã được chi tiết hóa thống kê đến từng trạm trong khu vực thông qua phương pháp hiệu chỉnh phân vị - QM 
(Quantile Mapping) [2]. Từ số liệu thu được, phần mềm thực hiện hai bước đánh giá theo thời gian và không gian với số liệu thực đo 30 năm quá khứ của 5 trạm trên khu vực nghiên cứu [3].

Đánh giá theo thời gian: Đối với mỗi trạm thời tiết, hệ số tương quan được tính của 36 cặp (10 ngày) trung bình 30 năm giữa $\mathrm{GCM}$ và dữ liệu thực đo (Hình 2a-2c).

Đánh giá theo không gian: Đối với mỗi giai đoạn 10 ngày, hệ số tương quan được tính của các trạm thời tiết trung bình 30 năm giữa $\mathrm{GCM}$ và dữ liệu thực đo (Hình 2d-2f).

Sau hai bước đánh giá trên, số liệu từ các GCM2 được xếp hạng về cả lượng mưa và nhiệt độ. Dựa vào kết quả từ phần mềm AIMS, nghiên cứu đã sử dụng số liệu khí tượng từ mô hình MIROC5 của Viện nghiên cứu khí quyển và đại dương (ĐH - Tokyo, Nhật Bản) cho lưu vực sông Sê San cho các bước đánh giá hạn khí tượng và thủy văn tiếp theo. Hình 3 dưới đây chỉ ra xếp hạng về lượng mưa và nhiệt độ từ các GCMs cho lưu vực Sê San.

Bảng 1. Danh muc mô hình khí hậu toàn cầu (GCMs) tù Dự án CMIP5

\begin{tabular}{|c|c|c|c|}
\hline GCMs & Mô hình & Nguồn & Quốc gia \\
\hline 1 & BCC-CSM1.1 & $\begin{array}{l}\text { Trung tâm Khí hậu Bắc Kinh, cục khí tượng Trung } \\
\text { Quốc }\end{array}$ & $\begin{array}{l}\text { Trung } \\
\text { Quốc }\end{array}$ \\
\hline 2 & CanESM2 & Trung tâm phân tích và mô hình khí hậu Canada & Canada \\
\hline 3 & CMCC-CM & Trung tâm Euro-Mediterranean về BĐKH & Ý \\
\hline 4 & CNRM-CM5 & $\begin{array}{l}\text { Trung tâm khí tượng thủy văn Pháp } \\
\text { Tổ chức Nghiên cứu Khoa học và Công nghiệp Liên }\end{array}$ & Pháp \\
\hline 5 & CSIRO-Mk3.6.0 & bang Úc & Úc \\
\hline 6 & INM-CM4 & Viện nghiên cứu mô hình khí hậu & Nga \\
\hline 7 & IPSL-CM5A-LR & Viện nghiên cứu Pierre-Simon Laplace & Pháp \\
\hline 8 & IPSL-CM5A-MR & Viện nghiên cứu Pierre-Simon Laplace & Pháp \\
\hline 9 & IPSL-CM5B-LR & Viện nghiên cứu Pierre-Simon Laplace & $\begin{array}{l}\text { Pháp } \\
\text { Trung }\end{array}$ \\
\hline 10 & FGOALS-g2 & Viện vật lý, khí quyển - viện khoa học Trung Quốc & $\begin{array}{l}\text { Quốc } \\
\text { Trung }\end{array}$ \\
\hline 11 & FGOALS-s2 & $\begin{array}{l}\text { Viện vật lý, khí quyển - viện khoa học Trung Quốc } \\
\text { Viện nghiên cứu khí quyền và đại dương ( ĐH - }\end{array}$ & Quốc \\
\hline 12 & MIROC5 & $\begin{array}{l}\text { Tokyo) } \\
\text { Viện nghiên cứu khí quyển và đại dương ( ĐH - }\end{array}$ & Nhật \\
\hline 13 & $\begin{array}{l}\text { MIROC-ESM } \\
\text { MIROC-ESM- }\end{array}$ & $\begin{array}{l}\text { Tokyo) } \\
\text { Viện nghiên cứu khí quyển và đại dương ( ĐH - }\end{array}$ & Nhật \\
\hline 14 & CHEM & Tokyo) & Nhật \\
\hline 15 & HadGEM2-CC & Trung tâm nghiên cứu khí tượng thủy văn Hadley & Anh \\
\hline 16 & HadGEM2-ES & Trung tâm nghiên cứu khí tượng thủy văn Hadley & $\begin{array}{l}\text { Anh } \\
\text { Hàn }\end{array}$ \\
\hline 17 & HadGEM2-A0 & Viện nghiên cứu khí tượng quốc gia & Quốc \\
\hline 18 & MPI-ESM-LR & Viện khí tượng học Max Planck & Đức \\
\hline 19 & MPI-ESM-MR & Viện khí tượng học Max Planck & Đức \\
\hline 20 & MRI-CGCM3 & Viện nghiên cứu khí tượng Nhật & Nhật \\
\hline 21 & CCSM4 & Trung tâm nghiên cứu khí quyển quốc gia Hoa Kỳ & Hoa Kỳ \\
\hline 22 & NorESM1-M & $\begin{array}{l}\text { Trung tâm khí hậu Nauy } \\
\text { Phòng thí nghiệm vật lý động lực học chất lỏng }\end{array}$ & Nauy \\
\hline 23 & GFDL-ESM2M & $\begin{array}{l}\text { NOAA } \\
\text { Phòng thí nghiệm vật lý động lực học chất lỏng }\end{array}$ & Hoa Kỳ \\
\hline 24 & GFDL-CM3 & $\begin{array}{l}\text { NOAA } \\
\text { Phòng thí nghiệm vật lý động lực học chất lỏng }\end{array}$ & Hoa Kỳ \\
\hline 25 & GFDL-ESM2G & NOAA & Hoa Kỳ \\
\hline 26 & CESM1(BGC) & Trung tâm nghiên cứu khí quyển quốc gia & \\
\hline 27 & CESM1(CAM5) & Trung tâm nghiên cứu khí quyển quốc gia Hoa Kỳ & Hoa Kỳ \\
\hline
\end{tabular}



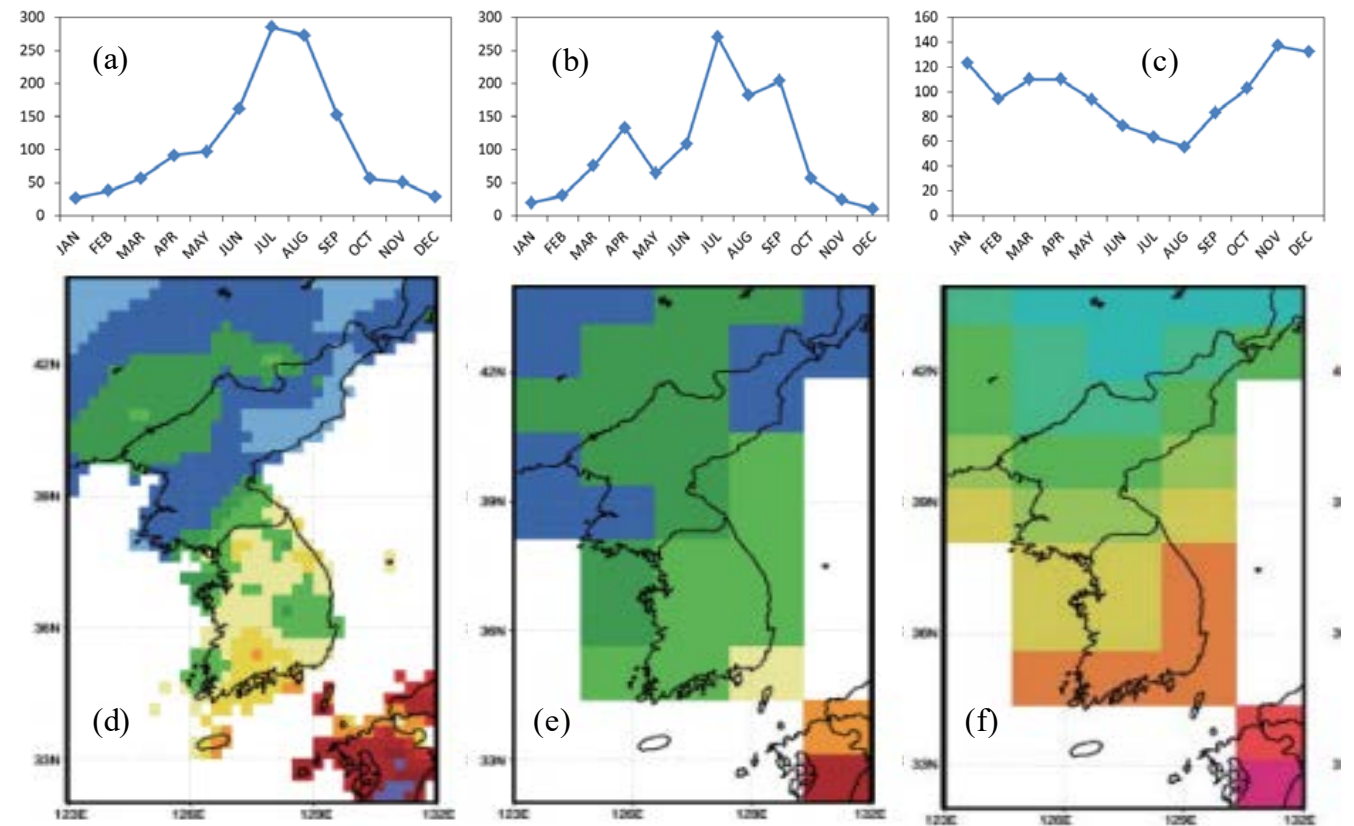

Hình 2. Đánh giá theo thời gian và không gian giũa số liệu thực đo, GCM1 và GCM2

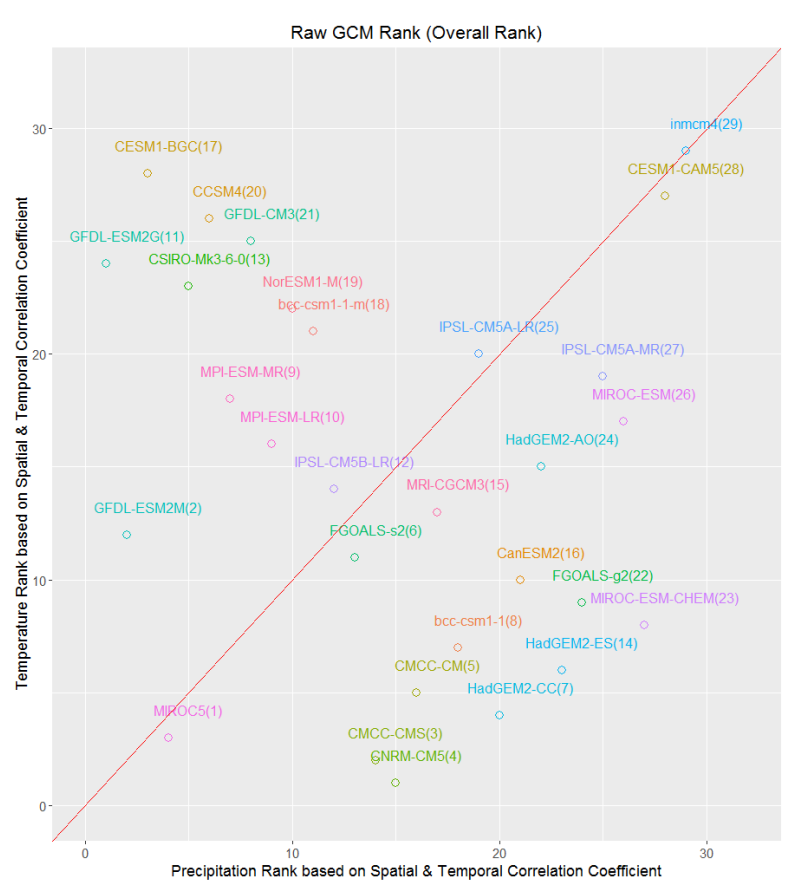

Hình 3. Xếp hạng về lượng mưa và nhiệt độ tì̀ các GCMs cho lưu vưc Sê San

\subsection{Chỉ số hạn khí tượng và hạn thủy văn}

Hạn hán khác các loại hình thiên tai khác là tác động của nó thường tích lũy chậm kéo dài trong nhiều năm và rất khó để có thể nhận biết được thời gian nào là bắt đầu và kết thúc của một trận hạn hán bởi vậy các định nghĩa về hạn hán thường mang tính địa phương cho từng khu vực [4]. Cũng bởi đặc tính của hạn hán nên trên thế giới hiện đã đưa ra rất nhiều phương pháp để tính toán chỉ số hạn khí tượng cũng như thủy văn nhưng kinh nghiệm cho thấy mỗi chỉ số sẽ có một ưu điểm vượt trội so với chỉ số khác hoặc ứng dụng phù hợp cho khu vực này nhưng lại không phù hợp cho khu vực khác. Trong nghiên cứu này, dựa vào điều kiện tự nhiên của lưu vực nghiên cứu và bộ số liệu đã được sưu tập, tác giả lựa chọn chỉ số chuẩn hóa lượng mưa SPI để đánh giá hạn khí tượng và hệ số $\mathrm{K}$ hạn để đánh giá thiếu hụt dòng chảy cho khu vực trong tương lai.

Chỉ số chuẩn hóa lượng mưa SPI: Năm 1993, SPI được mở rộng để phát hiện ra thời kì hạn và ẩm tại những qui mô thời gian khác nhau bởi McKee và cộng sự [5]. SPI tính toán cho bất cứ vùng nào dựa vào lượng mưa dài hạn cho một thời kì yêu cầu. Đầu tiên các số liệu này được hiệu chỉnh bằng hàm phân bố xác suất Gamma:

$$
G(x)=\frac{1}{\beta^{\alpha} \Gamma(\alpha)} x^{\alpha-1} e^{-x / \beta}
$$

Vì hàm phân bố Gamma là không xác định cho $\mathrm{x}=0$ và phân bố lượng mưa có thể chứa giá 
trị 0 nên xác suất tích lũy $\mathrm{H}(\mathrm{x})$ được tính:

$$
H(x)=q+(1-q) G(x)
$$

Trong đó: q là xác suất của giá trị 0 . Hàm phân bố này được chuyển thành một hàm phân bố chuẩn.

$$
\mathrm{SPI}=-\left(\mathrm{t}-\frac{\mathrm{c}_{0}+\mathrm{c}_{1} \mathrm{t}+\mathrm{c}_{2} \mathrm{t}^{2}}{1+\mathrm{d}_{1} \mathrm{t}+\mathrm{d}_{2} \mathrm{t}^{2}+\mathrm{d}_{3} \mathrm{t}^{3}}\right)
$$

khi $0<\mathrm{H}(\mathrm{x})<0,5$

$$
\mathrm{SPI}=+\left(\mathrm{t}-\frac{\mathrm{c}_{0}+\mathrm{c}_{1} \mathrm{t}+\mathrm{c}_{2} \mathrm{t}^{2}}{1+\mathrm{d}_{1} \mathrm{t}+\mathrm{d}_{2} \mathrm{t}^{2}+\mathrm{d}_{3} \mathrm{t}^{3}}\right)
$$

khi $0,5<\mathrm{H}(\mathrm{x})<1,0$

Tổng trị tuyệt đối các giá trị SPI cho tất cả các tháng xảy ra sự kiện hạn được định nghĩa là cường độ hạn. Bảng 1 trình bày các ngưỡng giá trị của SPI được xác định bởi McKee và cộng sự.

\section{Bảng 2. Phân cấp hạn theo chỉ số SPI}

\begin{tabular}{lc}
\hline \multicolumn{1}{c}{ Phân cấp hạn } & Khoảng giá trị SPI \\
\hline Hạn vừa & $-1,5<\mathrm{SPI}<-1,0$ \\
Hạn nặng & $-2,0<\mathrm{SPI}<-1,5$ \\
Hạn nghiêm trọng & $\mathrm{SPI}<-2,0$ \\
\hline
\end{tabular}

Hệ số K hạn: Là hệ số biểu thị mức độ hạn cho thời điểm xuất hiện và nơi sinh hạn cụ thể. Hệ số hạn được tính toán cho từng trạm KTTV trên lưu vực hoặc lân cận với lưu vực sông. Khạn được xác định khi đồng thời Kkhô và Kcạn là dương.

$$
\mathrm{K}_{\text {han }}=\sqrt{\mathrm{K}_{\mathrm{Kho}} \mathrm{K}_{\text {can }}}
$$

Bảng 3. Phân cấp mức độ hạn theo chỉ số Khan

\begin{tabular}{lc}
\hline \multicolumn{1}{c}{ Mức độ hạn } & Giá trị \\
\hline Dấu hiệu sinh hạn & Khạn $=0,5$ \\
Hạn nhẹ & $0,5<$ Khạn $<0,6$ \\
Hạn vừa & $0,6<$ Khạn $<0,8$ \\
Hạn nặng & $0,8<$ Khạn $<0,95$ \\
Hạn đặc biệt & $0,95<$ Khạn $<1$ \\
\hline
\end{tabular}

\subsection{Mô hình thủy văn SWAT}

Để đánh giá hạn thủy văn trên lưu vực Sê San trong các thời kỳ tương lai dựa vào số liệu khí tượng từ mô hình MIROC5, nghiên cứu lựa chọn mô hình thủy văn SWAT để mô phỏng dòng chảy tương lai cho lưu vực. SWAT (Soil and Water Assessment Tool) là công cụ đánh giá nước và đất được xây dựng bởi tiến sĩ Jeff Arnold ở Trung tâm Phục vụ Nghiên cứu Nông nghiệp (ARS- Agricultural Research Service) thuộc Bộ Nông nghiệp Hoa Kỳ (USDA- United States Department of Agriculture) [6] và giáo sư Srinivasan thuộc Đại học Texas A\&M, Hoa Kỳ. SWAT cho phép mô hình hóa nhiều quá trình vật lý trên cùng một lưu vực. Mô hình SWAT có nhiều ưu điểm so với các mô hình trước đó là khi mô phỏng SWAT sẽ phân chia lưu vực lớn thành các tiểu lưu vực, các đơn vị thủy văn dựa trên bản đồ sử dụng đất, thổ nhưỡng, địa hình để tăng mức độ chi tiết mô phỏng về mặt không gian. SWAT mô hình hóa chu trình nước dựa trên cơ sở phương trình cân bằng nước sau:

$\mathrm{SW}_{\mathrm{t}}=\mathrm{SW}_{0}+\sum_{\mathrm{i}=1}^{\mathrm{t}}\left(\mathrm{R}_{\text {day }}-\mathrm{Q}_{\text {surf }}-\mathrm{E}_{\mathrm{a}}-\mathrm{w}_{\text {seep }}-\mathrm{Q}_{\mathrm{gw}}\right)(6)$

Trong đó $\mathrm{SWt}$ là lượng nước trong đất tại thời điểm $\mathrm{t}(\mathrm{mm})$; SW0 là lượng nước trong đất tại thời điểm ban đầu trong ngày thứ $\mathrm{i}(\mathrm{mm})$; Rday là lượng nước mưa trong ngày thứ $\mathrm{i}(\mathrm{mm})$; Qsurf là lượng dòng chảy bề mặt trong ngày thứ $\mathrm{i}$ (mm); Ea là lượng nước bốc hơi trong ngày thứ i (mm); Qgw là lượng nước ngầm chảy ra sông trong ngày thứ i (mm).

Mô hình còn có khả năng dự báo thông qua việc thay đổi dữ liệu đầu vào (quản lí sử dụng đất, khí hậu, thực vật...) đều định lượng được những tác động của sự thay đổi đến dòng chảy ra của các lưu vực hoặc các thông số khác; có hiệu quả cao, có thể tính toán và mô phỏng trên lưu vực rộng lớn hoặc hỗ trợ ra quyết định đối với những chiến lược quản lí đa dạng, phức tạp với sự đầu tư kinh tế và thời gian thấp; cho phép người sử dụng nghiên cứu những tác động trong thời gian dài.

Trong nghiên cứu này, dữ liệu đầu vào cho mô hình được thu thập từ các nguồn tài liệu đã liệt kê ở trên và được xây dựng thành các loại bản đồ cho lưu vực sông Sê San như các hình được trình bày dưới đây. Lưu vực sông Sê San được chia thành 44 tiểu lưu vực. 

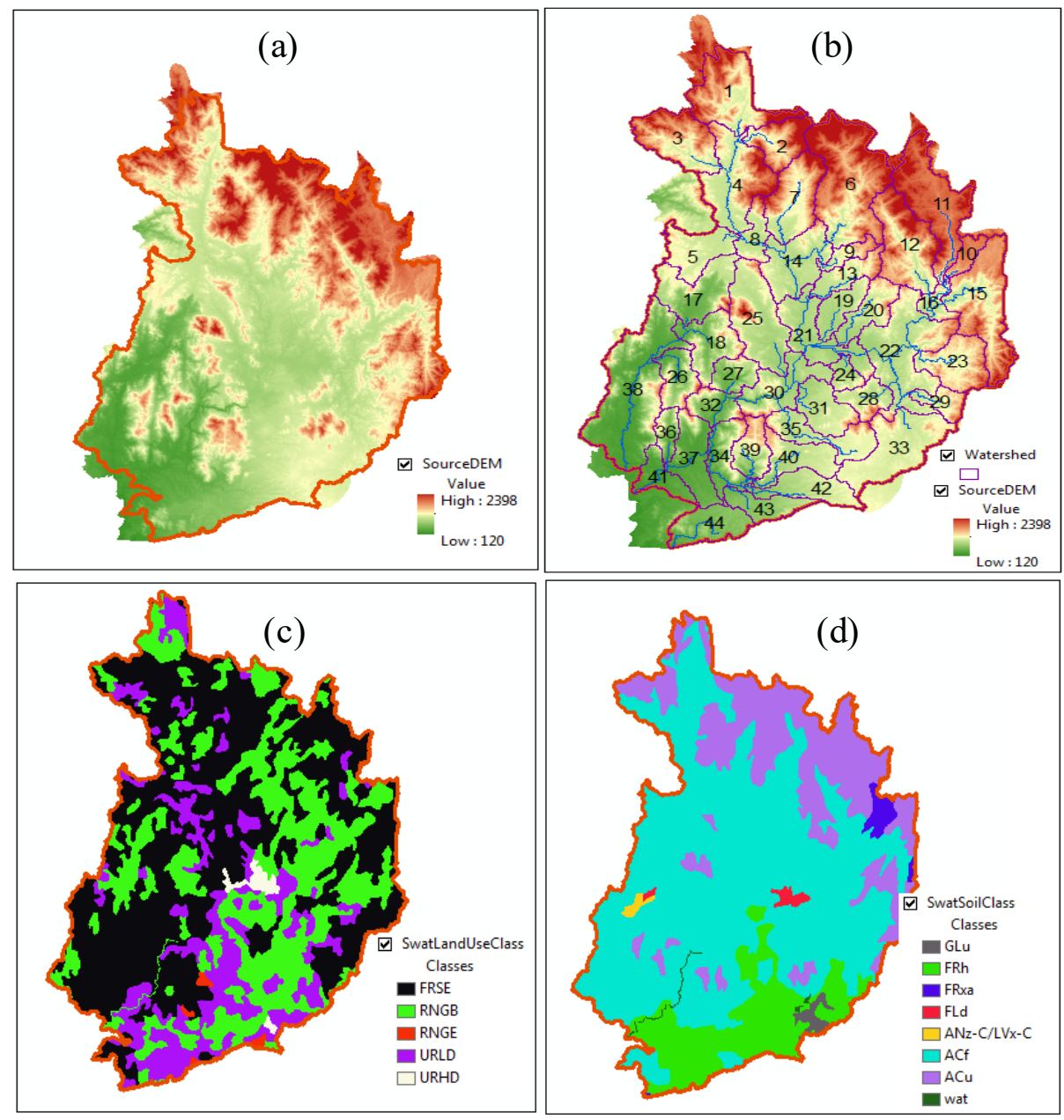

Hình 3. (a) Bản đồ DEM lưu vưc sông Sê San; (b) Bản đồ Phân chia tiểu lưu vưcc; (c) Bản đồ các loại hình sư dụng đất; (d) Bản đồ phân loại đất trong lưu vực

\section{Kết quả và thảo luận.}

\section{1. Đánh giá hạn khí tượng}

Số liệu lượng mưa trong giai đoạn 30 năm quá khứ từ 1980 đến 2010 được sử dụng để đánh giá lại chỉ số hạn SPI theo thời gian 6 tháng (thể hiện kết quả theo mùa) và 12 tháng (thể hiện kết quả theo năm) nhận thấy các sự kiện hạn diễn ra khá thường xuyên vào mùa khô các giai đoạn 1981-1982, 1992-1993, 1996-1997, 2005-2006; trong đó đợt hạn khắc nhiệt nhất được ghi nhận trong quá khứ là ở giai đoạn 1996-1997 và 2005-2006.

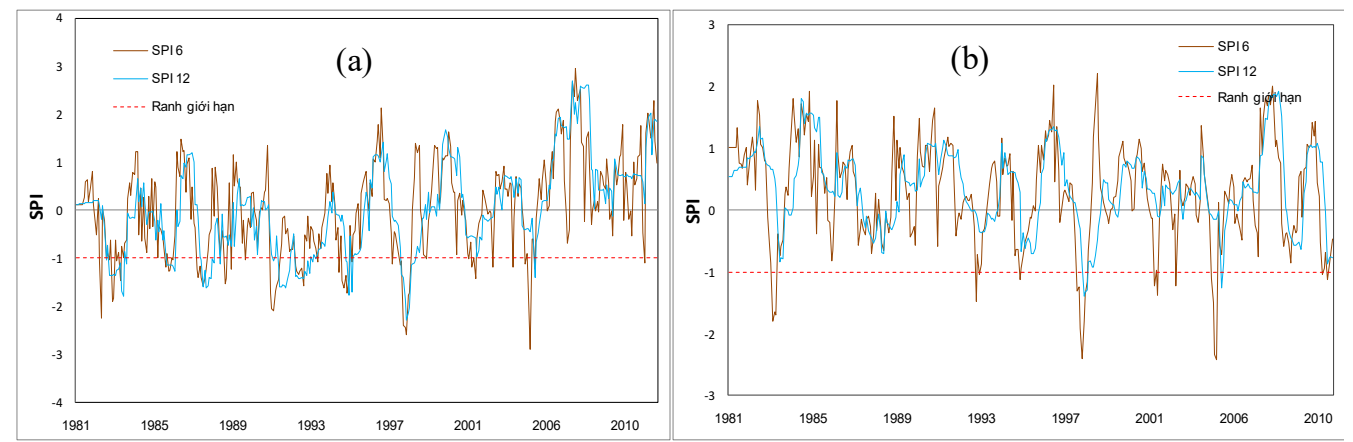

Hình 4. Đồ thị biểu diễn chỉ số SPI6 và SPI12 tại các trạm: (a) Kontum; (b) Pleiku 


\section{BÀI BÁO KHOA HỌC}

Sự thay đổi lượng mưa trong tương lai sẽ ảnh hưởng đến tình trạng hạn hán, dựa vào số liệu mưa từ mô hình MIROC5 sau khi đã được chi tiết hóa đến các trạm khí tượng trên khu vực, nghiên cứu tiếp tục đánh giá chỉ số SPI6 và SPI12 trong 3 giai đoạn trong tương lai gồm 2016 - 2035, 2046 - 2065, 2086 - 2099 với 2 kịch bản phát thải trung bình $\mathrm{RCP} 4.5$ và kịch bản phát thải cao RCP 8.5.

Trong giai đoạn đầu tiên 2016 - 2035 cho hai kịch bản phát thải nhận thấy có tổng số khoảng 38 - 42 sự kiện hạn được đánh giá trên số liệu mưa từ các trạm khí tượng ( trong đó có khoảng $55 \%$ là hạn vừa, $30 \%$ hạn nặng và $15 \%$ nghiêm trọng cho kịch bản RCP 8.5), các sự kiện hạn liên tục diễn ra vào khoảng thời gian từ 2023 đến 2028 trên các trạm khí tượng trong khu vực nghiên cứu với sự kiện hạn diễn ra nặng nhất vào khoảng giai đoạn từ 2027 - 2028 cho kịch bản phát thải RCP 8.5.

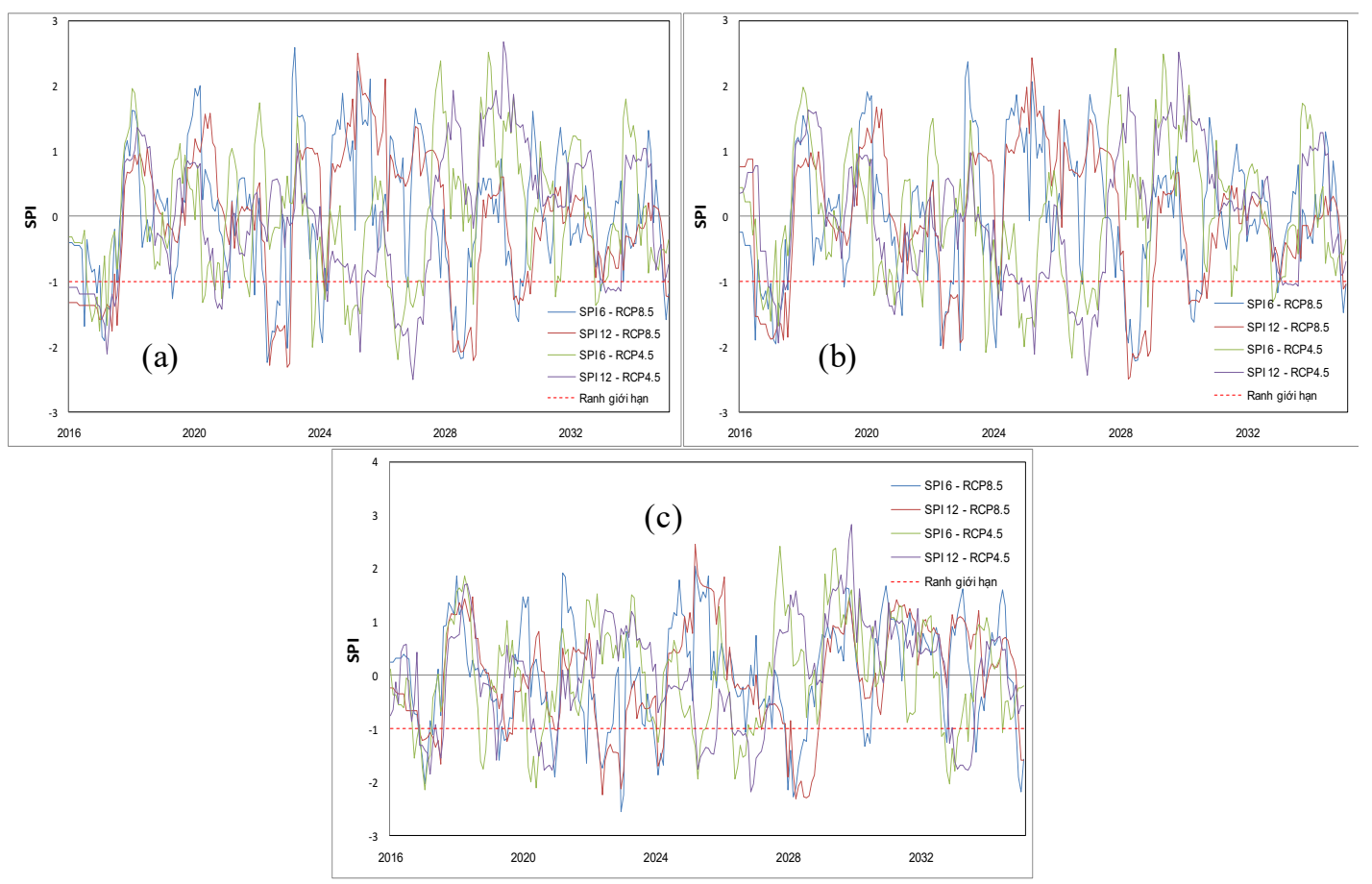

Hình 5. Đồ thị biểu diê̂n chỉ số SPI6 và SPI12 giai đoạn 2016-2035 tại các trạm: (a) Đăk Tô; (b) Kom Tum; (c) Pleiku

Trong giai đoạn tiếp theo từ 2046 - 2065 cho hai kịch bản phát thải nhận thấy có tổng số khoảng 32 - 35 sự kiện hạn được đánh giá trên số liệu mưa từ các trạm khí tượng ( trong đó có khoảng 58\% hạn vừa, $42 \%$ hạn nặng cho kịch bản RCP 8.5), các sự kiện hạn diễn ra vào khoảng thời gian từ 2051-2052, 2054-2055, 2058-2059 và 2062-2063 trên các trạm khí tượng trong khu vực nghiên cứu với sự kiện hạn diễn ra nặng nhất vào khoảng giai đoạn từ 2062-2063 cho kịch bản phát thải RCP 8.5.
Trong giai đoạn cuối cùng từ 2080 - 2099 cho hai kịch bản phát thải nhận thấy có tổng số khoảng 39-41 sự kiện hạn được đánh giá trên số liệu mưa từ các trạm khí tượng ( trong đó có khoảng 35\% hạn vừa, $47 \%$ hạn nặng và $18 \%$ hạn nghiêm trọng cho kịch bản RCP 8.5), các sự kiện hạn diễn liên tục vào khoảng thời gian từ 2081 2086 và từ năm 2089 - 2094 trên các trạm khí tượng trong khu vực nghiên cứu với sự kiện hạn diễn ra nặng nhất vào khoảng giai đoạn từ 2085 -2086 cho kịch bản phát thải RCP 8.5. 


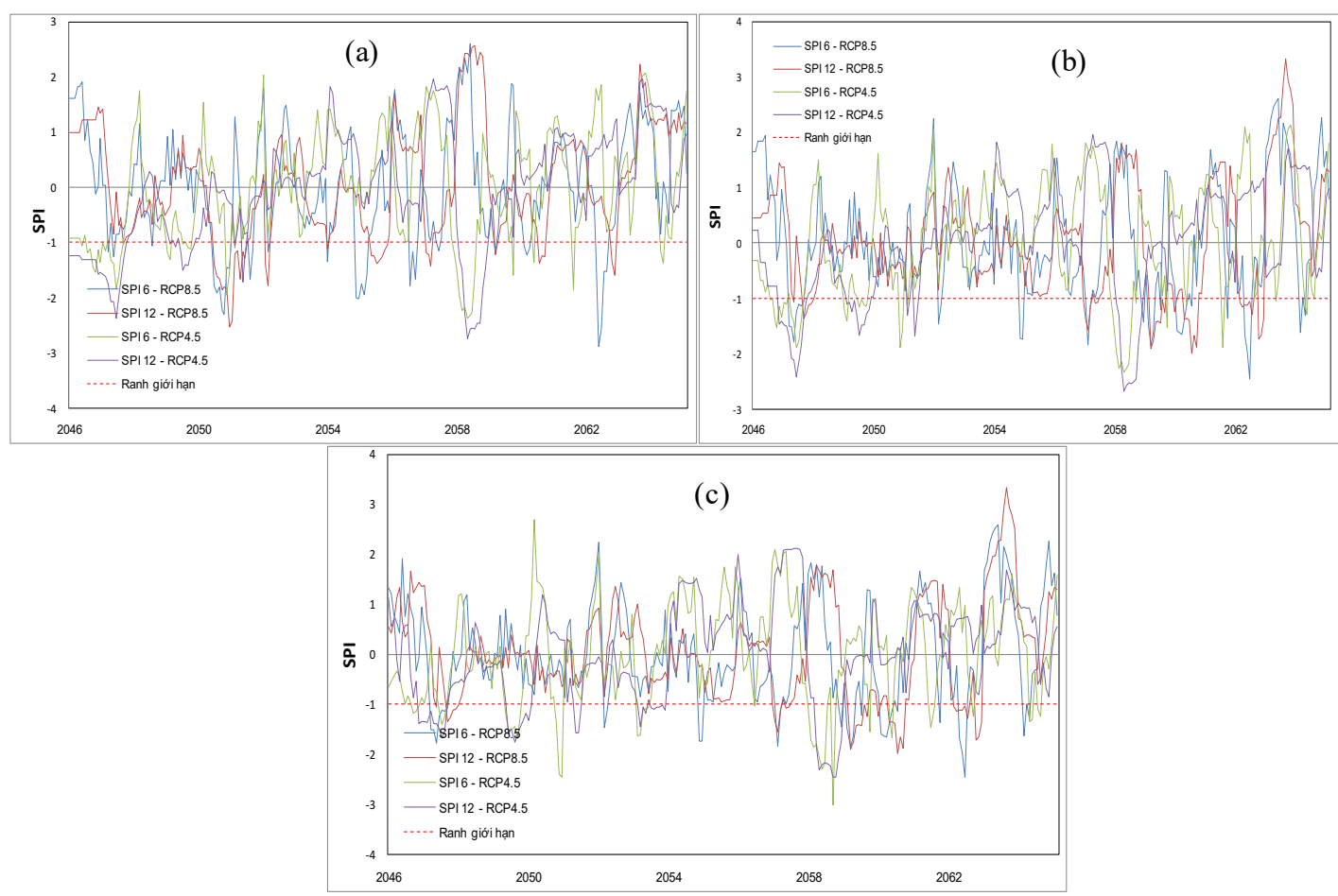

Hình 6. Đồ thị biểu diễn chỉ số SPI6 và SPI12 giai đoạn 2046 - 2065 tại các trạm: (a) Đăk Tô; (b) Kon Tum; (c) Pleiku

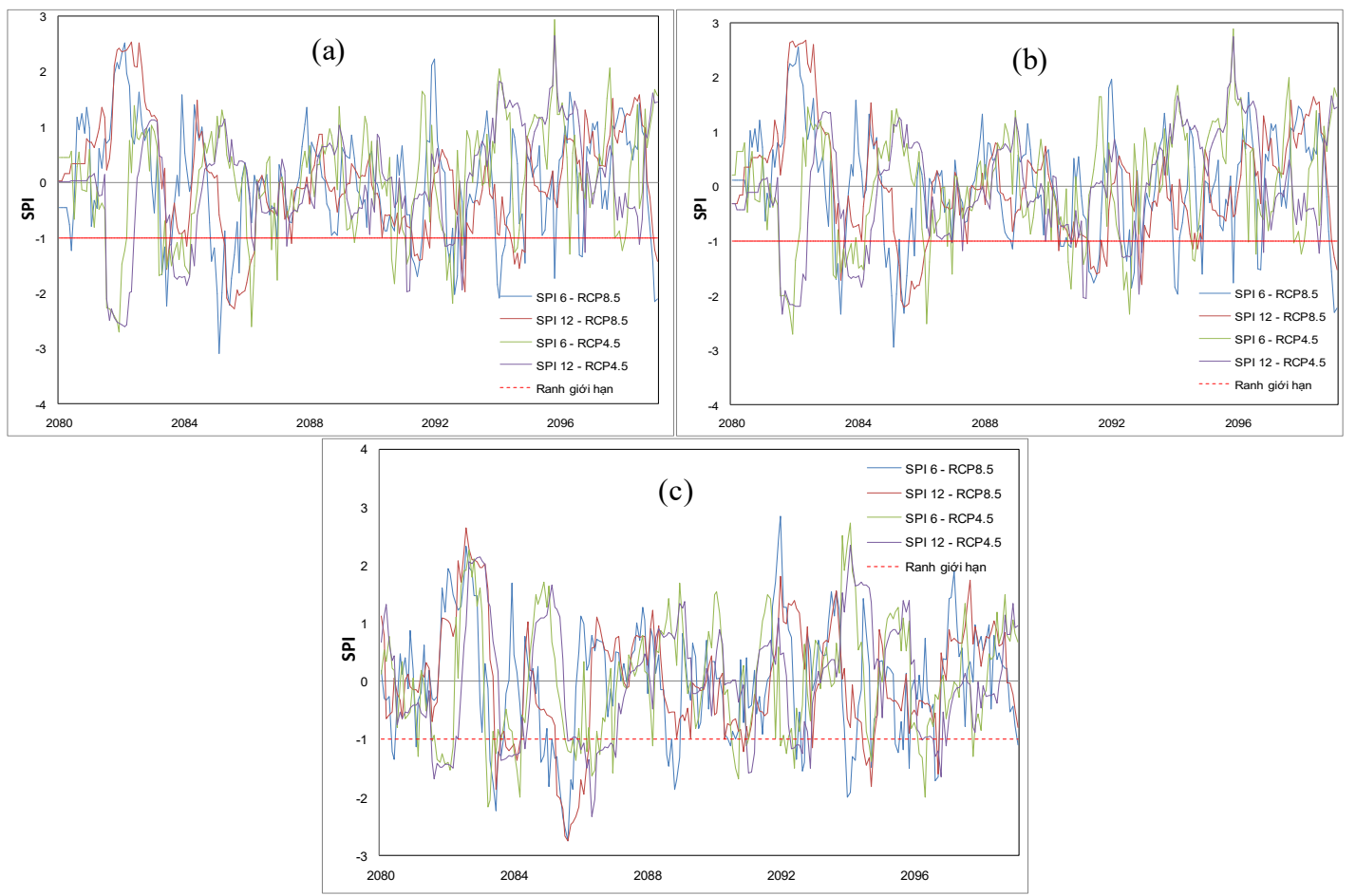

Hình 7. Đồ thị biểu diễn chỉ số SPI6 và SPI12 giai đoạn 2080 - 2099 tại các trạm: (a) Đăk Tô; (b) Kon Tum; (c) Pleiku 


\section{BÀI BÁO KHOA HỌC}

\section{2. Đánh giá hạn thủ̉y văn}

Lưu lượng dòng chảy được hiệu chỉnh và kiểm định trong mô hình thủy văn SWAT với chuỗi thời gian 30 năm trong quá khứ từ năm 1980 - 2016 của 2 trạm thủy văn KonPlong và
Đăk Tô. Trong đó thời gian hiệu chỉnh là từ năm 1980 đến 2005 và thời gian kiểm định là từ năm 2006 - 2016 cho kết quả được thể hiện trong hình $8 \mathrm{a}-8 \mathrm{f}$.

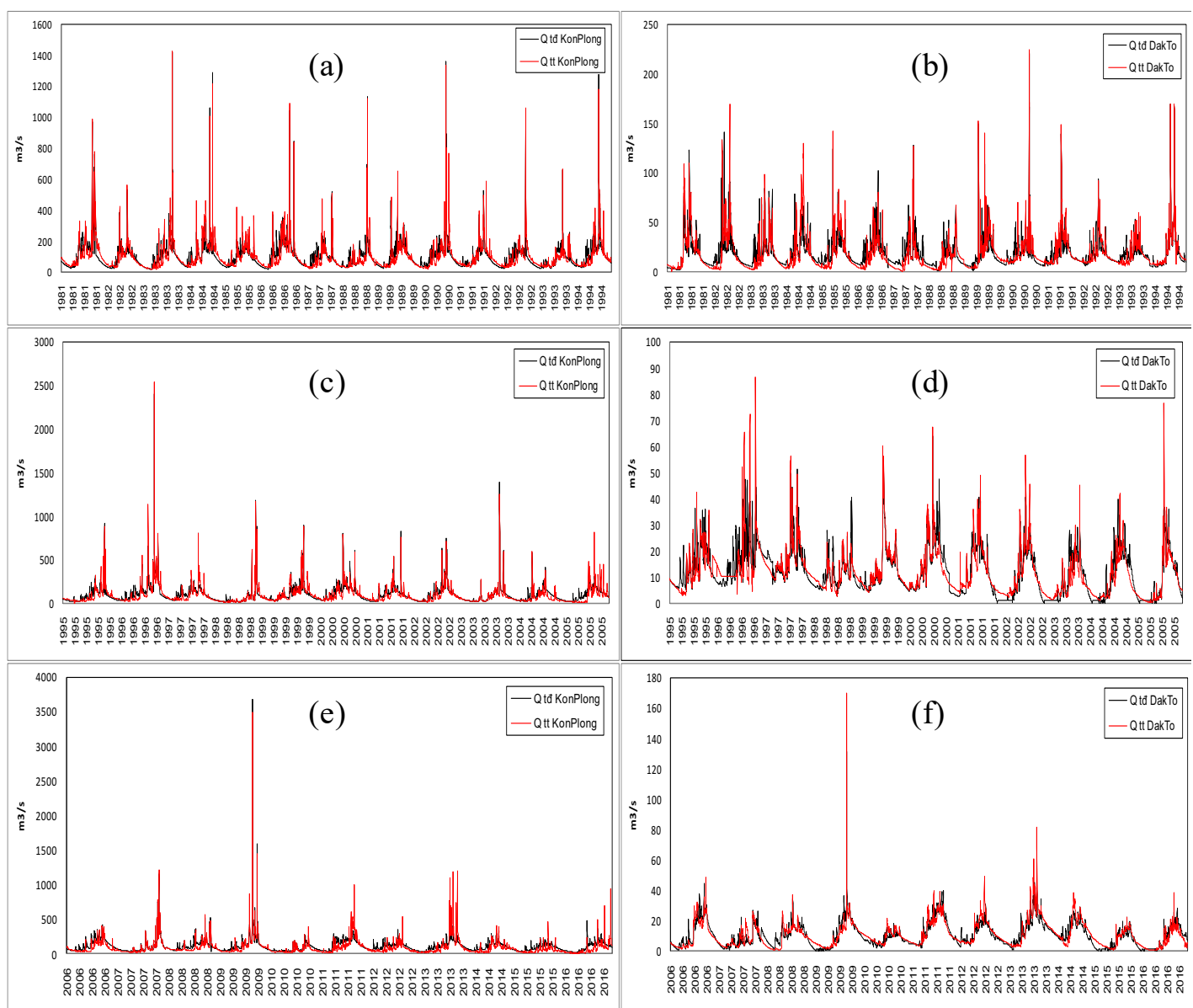

Hình 8. Quá trình hiệu chỉnh lưu lương tại các trạm: (a) KonPlong 1980-1994; (b) Đăk Tô 19801994; (c) KonPlong 1995 -2000; (d) Đăk Tô 1995 -2005; (e) KonPlong 2006-2016;

\section{(f) Đăk Tô 2006-2016}

Quá trình hiệu chỉnh được hiệu chỉnh tự động bằng phần mềm SWAT-CUP với thuật toán SUFI-2 (Semi Automated Sequential Uncertainty Fitting). Quá trình hiệu chỉnh được thực hiện riêng lẻ ứng với từng trạm thủy văn với nguyên tắc hiệu chỉnh từ trạm thượng nguồn đến trạm ở hạ nguồn [7]. Giá trị các thông số của mô hình được thể hiện như trong bảng 4 .

Kết quả, lưu lượng dòng chảy mô phỏng được đánh giá thông qua các chỉ số thống kê. Căn cứ theo các mức độ phân cấp của D.N. Moriasi (2007), kết quả mô phỏng lưu lượng dòng chảy tại 2 trạm đều đạt mức tốt hệ số NSE, R2 đạt từ 0,7 trở lên và PBIAS ở mức rất đạt.

Sau quá trình hiệu chỉnh và kiểm định mô hình để tìm ra bộ thông số phù hợp cho lưu vực nghiên cứu, bộ thông số đó tiếp tục được sử dụng để mô phỏng dòng chảy cho tương lai với 2 kịch bản phát thải tương ứng là RCP 4.5 và $R C P$ 8.5. Với số liệu dòng chảy thu được trong tương lai, nghiên cứu đã sử dụng chỉ số hạn thủy văn $\mathrm{K}$ hạn để xây dựng bản đồ phân vùng hạn hán cho lưu vực sông Sê San trong các tháng mùa khô. Các bản đồ hạn hán được xây dựng cho 3 khoảng thời gian trong tương lai là 2016-2035, 2046-2065, 2080-2099. Trong mỗi giai đoạn, dựa vào khoảng thời gian hạn nặng nhất đã được đánh giá trong phần hạn khí tượng, chỉ số K hạn được tính toán tương ứng từ dòng chảy cho 43 tiểu lưu vực. 
Bảng 4. Bộ thông số mô hình SWAT trong thời gian hiệu chỉnh

\begin{tabular}{|c|c|c|c|}
\hline \multirow{2}{*}{ Tham số } & \multirow{2}{*}{ Ý nghĩa } & \multicolumn{2}{|c|}{ Giá trị } \\
\hline & & Konplong & Đăk Tô \\
\hline r_CN2 & $\begin{array}{l}\text { Hệ số CN ứng với điều kiện ẩm } \\
\text { II (\%) }\end{array}$ & -1.15 & $-1,89$ \\
\hline v_SURLAG & Hệ số trễ dòng chảy mặt (ngày) & 7,74 & 13,88 \\
\hline v_ESCO & Hệ số bốc hơi của đất & 0,008 & 0,03 \\
\hline v_SÖLAWC & Khả năng trữ nước của đất & 0,32 & 0,13 \\
\hline$\overline{\mathrm{v}} \mathrm{S} S \mathrm{SOL}$ BD & Dung trọng của lớp đất $\left(\mathrm{g} / \mathrm{cm}^{3}\right)$ & 0,85 & 1,55 \\
\hline v_CH_N2 & Hệ số nhám của sông chính & 0,31 & - \\
\hline v_ĀLPHA_BF & Hệ số triết giảm dòng chảy ngầm & 0,42 & 0,37 \\
\hline v_GW_DELAY & $\begin{array}{l}\text { Thời gian trữ nước tầng ngầm } \\
\text { (ngày) }\end{array}$ & 120,0 & 106,94 \\
\hline v_GWQMN & $\begin{array}{l}\text { Ngướng sinh dòng chảy ngầm } \\
(\mathrm{mm})\end{array}$ & 1002,0 & 5562,1 \\
\hline v_GW_REVAP & Hệ số tái bốc hơi nước ngầm & 0,12 & 0,15 \\
\hline
\end{tabular}

Bảng 5. Đánh giá các chỉ tiêu cho chất lương mô phỏng của mô hình

\begin{tabular}{cccc}
\hline \multirow{2}{*}{ Chỉ tiêu đánh giá } & \multicolumn{2}{c}{ Trạm thủy văn } & \multirow{2}{*}{ Chất lượng } \\
\cline { 2 - 3 } & KonPlong & Đăk Tồ & \\
\hline NSE & 0.76 & 0.78 & Đạt \\
PBIAS & 10 & 12 & Đạt \\
R $^{2}$ & 0.7 & 0.7 & Đạt \\
\hline
\end{tabular}

Đối với kịch bản RCP 4.5, các sự kiện hạn tổng số 28 tiểu lưu vực, sự kiện hạn vừa xuất được ghi nhận vào các tháng mùa khô trong giai hiện trên tổng số 8 tiểu lưu vực. Các khu vực đoạn 2058-2059 và 2085-2086. Đối với giai xuất hiện hạn vừa được ghi nhận trên tỉnh Gia đoạn 2058-2059, sự kiện hạn nhẹ xuất hiện trên Lai thuộc lưu vực sông Sê San. Từ kết quả tính tổng số 23 tiểu lưu vực, sự kiện hạn vừa xuất toán hệ số $\mathrm{K}$ hạn, bản đồ phân cấp hạn trên lưu hiện trên tổng số 7 tiểu lưu vực. Đối với giai vực Sê San xây dựng dưới sự hỗ trợ của hệ thống đoạn 2085-2086, sự kiện hạn nhẹ xuất hiện trên thông tin địa lý (GIS) như hình dưới đây.

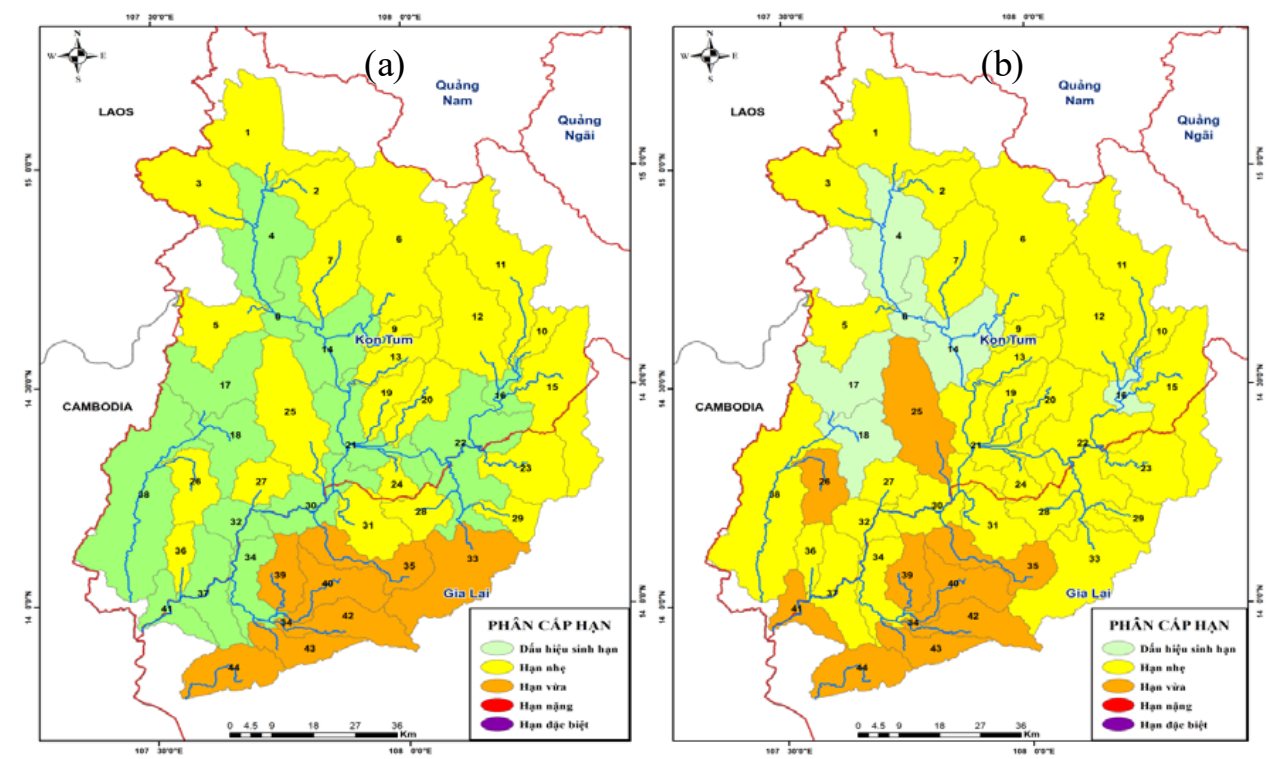

Hình 9. Bản đồ phân cấp hạn theo kịch bản RCP 4.5 giai đoạn: (a) 2058-2059; (b) 2085-2086 


\section{BÀI BÁO KHOA HỌC}

Đối với kịch bản RCP 8.5, các sự kiện hạn được ghi nhận vào các tháng mùa khô trong giai đoạn 2062 - 2063 và 2085 - 2086. Đối với giai đoạn 2062 - 2063, chủ yếu xuất hiện sự kiện hạn vừa và hạn nặng với sự kiện hạn nhẹ xuất hiện trên tổng số 23 tiểu lưu vực, sự kiện hạn nặng xuất hiện trên tổng số 7 tiểu lưu vực. Đối với giai đoạn 2085 - 2086, sự kiện hạn nhẹ xuất hiện trên

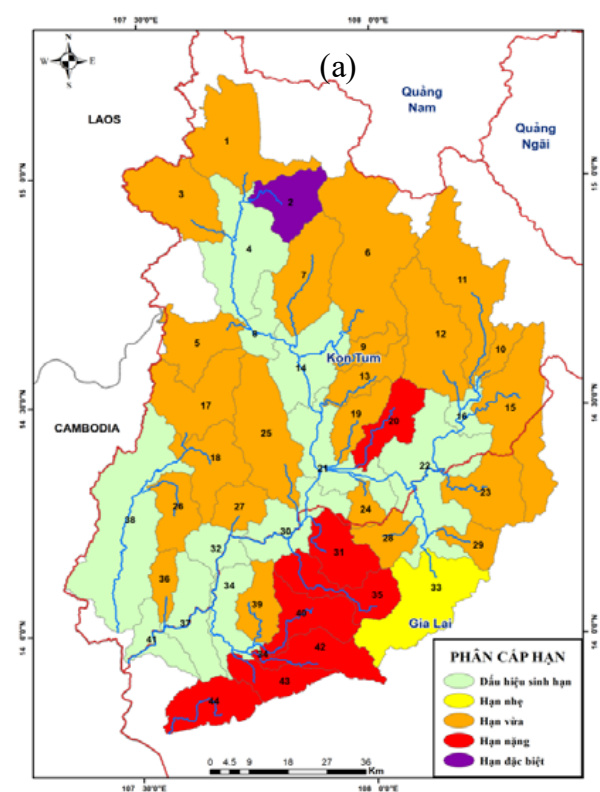

Hình 10. Bản đồ phân cấp hạn theo kịch bản RCP 8.5 giai đoạn: (a) 2062-2063; (b) 2085-2086

\section{Kết luận và kiến nghị}

Trong nghiên cứu này, số liệu khí tượng từ mô hình toàn cầu MIROC5 đã được sử dụng để đánh giá hạn hạn cho lưu vực sông Sê San dưới tác động của biến đổi khí hậu. Chỉ số hạn khí tượng SPI, chỉ số hạn thủy văn $\mathrm{K}$ cạn được sử dụng để đưa ra được bức tranh về dự báo hạn xảy ra trong một số giai đoạn trong tương lai với hai kịch bản phát thải thấp RCP 4.5 và kịch bản phát thải cao RCP 8.5. Đối với hạn khí tượng, chỉ số SPI ghi nhận trong giai đoạn từ 2080 đến 2099 với tổng số sự kiện hạn được ghi nhận khoảng 41 sự kiện hạn được đánh giá trên số liệu mưa từ các trạm khí tượng (trong đó có khoảng 35\% hạn vừa, $47 \%$ hạn nặng và $18 \%$ hạn nghiêm trọng cho kịch bản RCP 8.5), giai đoạn từ 2045- 2065 được ghi nhận với số sự kiện hạn xảy ra ít hơn hai giai đoạn còn lại tuy nhiên lại giai đoạn có khoảng thời gian từ 2062 - 2063 xảy ra hạn nghiêm trọng nhất trong chuỗi từ 2016 - 2099.

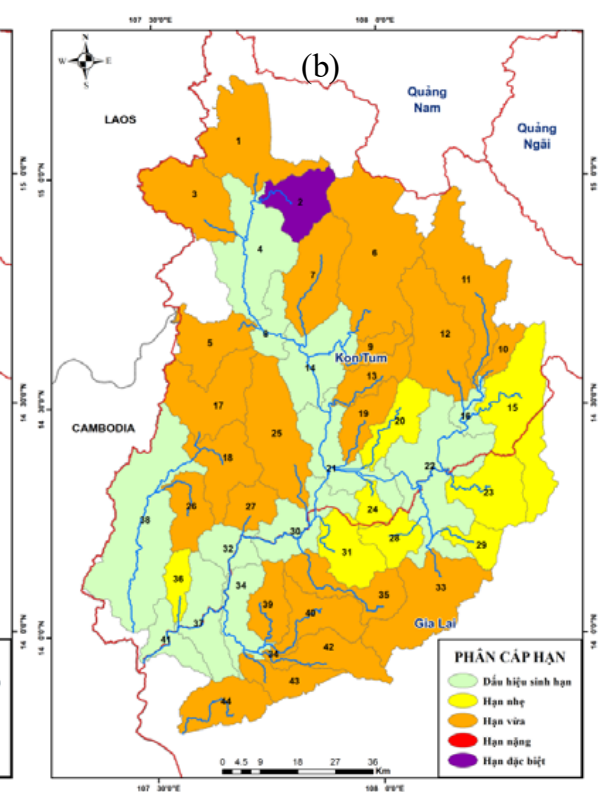

tổng số 9 tiểu lưu vực, sự kiện hạn vừa xuất hiện trên tổng số 24 tiểu lưu vực. Các khu vực xuất hiện hạn vừa và nặng được ghi nhận trên tỉnh Gia Lai thuộc lưu vực sông Sê San. Từ kết quả tính toán hệ số $\mathrm{K}$ hạn, bản đồ phân cấp hạn trên lưu vực Sê San xây dựng dưới sự hỗ trợ của hệ thống thông tin địa lý (GIS) như hình dưới đây:

Mô hình SWAT được sử dụng để mô phỏng quá trình dòng chảy trong quá khứ với chuỗi thời gian 30 năm từ 1980 đến 2016 cho kết quả hiệu chỉnh và kiểm định tương đối tốt nên kết quả mô hình đưa ra để mô phỏng dòng chảy trong tương lai từ 2016-2099 có tính hợp lý trong nghiên cứu. Dựa vào số liệu dòng chảy được mô phỏng trong tương lai và chỉ số hạn thủy văn $\mathrm{K}$ hạn, nghiên cứu đã đưa ra được bản đồ phân vùng hạn hán cho 44 tiểu lưu vực trên sông Sê San, giúp đưa ra cái nhìn tổng quan về mức độ hạn thủy văn trên lưu vực trong tương lai dưới tác động của biến đổi khí hậu, nhận thấy các tiểu lưu vực thuộc khu vực tỉnh Gia Lai sẽ chịu ảnh hưởng nặng nhất về hạn thủy văn. Kết quả hi vọng sẽ là tài liệu tham khảo có tính ứng dụng cao cho quy hoạch hoặc sử dụng tài nguyên nước trong tương lai cho lưu vực sông. 
Lời cảm ơn: Các nội dung nghiên cứu trên nằm trong khuôn khổ của đề tài "Nghiên cứu co" sở khoa học và thực tiễn phuc vu cảnh báo cấp độ rủi ro thiên tai do hạn hán cho các địa phưong thuộc khu vưc Tây Nguyên trong điều kiện biến đổi khi hậu”, mã số: TNMT.2017.05.21.

1. https://aims.apcc21.org/

\title{
Tài liệu tham khảo
}

2. Cannon, A.J., Sobie, S.R., Murdock, T.Q., (2015), Bias Correction of GCM Precipitation by Quantile Mapping: How Well Do Methods Preserve Changes in Quantiles and Extremes. Journal of Climate, 28 (17), 150722131126009. DOI: 10.1175/JCLI-D-14-00754.1.

3. Hwang, S., Graham, W.D., (2013), Development and comparative evaluation of a stochastic analog method to downscale daily GCM precipitation. Hydrology and Earth System Sciences, 17, 4481-4502. Doi:10.5194/hess-17-4481-2013.

4. Nguyễn Quang Kim (2005), Nghiên cưu dụ báo hạn hán vùng Nam Trung Bộ và Tây Nguyên và xây dựng các giải pháp phòng chống.

5. McKee, T.B., Doesken, N.J., Kleist, J., (1993), The relationship of drought frequency and duration to time scales. Proceedings of the $8^{\text {th }}$ Conference of Applied Climatology, 17-22 January 1993.

6. Arnold, J.G. et al. Large Area Hydrologic Modelling and Assessment Part I: Model Development. Journal of American Water Resources Association, 34 (1), 73-89.

7. Nguyễn Thị Ngọc Quyên, Nguyễn Duy Liêm, Nguyễn Đại Ngưỡng, Nguyễn Thoan, Bùi Tá Long, Nguyễn Kim Lợi (2017), Phân vùng hạn hán dựa trên chỉ số hạn và mô phỏng chế độ thủy văn trên lưu vực Srepok vùng Tây Nguyên. Tạp chí Khoa học ĐHQGHN: Các Khoa học Trái đất và Môi trường, 33 (1), 65-81.

\section{EVALUATION ON THE IMPACT OF CLIMATE CHANGE ON DROUGHT IN SE SAN RIVER BASIN}

\author{
Vu Duc Long', Nguyen Ngoc Hoa ${ }^{1}$ \\ ${ }^{1}$ National center of hydro-meteorological forecasting
}

\begin{abstract}
The paper presents the impact of climate change on meteorological and hydrological drought during the dry season in the Se San river basin through drought indices and hydrological model. This study used two climate change scenarios RCP 4.5 and RCP 8.5 from Global Climate Models of Coupled Model Intercomparison Project 5 (CMIP5) and the data of two scenarios are applied statistical downscaling methods for Se San river basin. Standardized Precepitation Index (SPI) is used to calculate meteorological drought. The potential evaporation, precipitation and flow extracted from the SWAT model were used as inputs for calculating the hydrological drought. The evaluation results in the future show that meteorological drought occurs most often in the period from 2080 to 2099 with 41 dry events were recorded (about 35\% moderately dry, 47\% severely dry and $18 \%$ extremely dry for RCP 8.5 scenario), this study also gave drought-level zoning maps for the years when occurred extremely dry. This result indicated that all sub-basin of Gia Lai province will be the most vulnerable by hydrological drought.
\end{abstract}

Keywords: Climate change, Drought indices, SWAT model, Se San River basin. 